Bond University

Research Repository

\title{
Shared decision making in Australia in 2017
}

Trevena, Lyndal J.; Shepherd, Heather L.; Bonner, Carissa; Jansen, Jesse; Cust, Anne E; Leask, Julie; Shadbolt, Narelle; Del Mar, Chris; McCaffery, Kirsten J; Hoffmann, Tammy

Published in:

Zeitschrift fur Evidenz, Fortbildung und Qualitat im Gesundheitswesen

DOI:

10.1016/j.zefq.2017.05.011

Licence:

CC BY-NC-ND

Link to output in Bond University research repository.

Recommended citation $(A P A)$ :

Trevena, L. J., Shepherd, H. L., Bonner, C., Jansen, J., Cust, A. E., Leask, J., Shadbolt, N., Del Mar, C.

McCaffery, K. J., \& Hoffmann, T. (2017). Shared decision making in Australia in 2017. Zeitschrift fur Evidenz, Fortbildung und Qualitat im Gesundheitswesen, 123-124, 17-20. https://doi.org/10.1016/j.zefq.2017.05.011

\footnotetext{
General rights

Copyright and moral rights for the publications made accessible in the public portal are retained by the authors and/or other copyright owners and it is a condition of accessing publications that users recognise and abide by the legal requirements associated with these rights.

For more information, or if you believe that this document breaches copyright, please contact the Bond University research repository coordinator.
} 


\title{
Shared decision making in Australia in 2017
}

\section{Partizipative Entscheidungsfindung in Australien im Jahr 2017}

\author{
Lyndal Trevena $^{\mathrm{a}, *}$, Heather L Shepherd $^{\mathrm{b}}$, Carissa Bonner ${ }^{\mathrm{a}}$, Jesse Jansen ${ }^{\mathrm{c}}$, Anne E Cust ${ }^{\mathrm{d}}$, \\ Julie Leask $^{\mathrm{e}}$, Narelle Shadbolt ${ }^{\mathrm{f}}$, Chris Del Mar ${ }^{\mathrm{g}}$, Kirsten McCaffery ${ }^{\mathrm{h}}$, Tammy Hoffmann ${ }^{\mathrm{g}}$ \\ a ASK-GP Centre of Research Excellence, Sydney School of Public Health, University of Sydney, NSW, Australia \\ ${ }^{\mathrm{b}}$ ASK-GP Centre of Research Excellence, CeMPED, School of Public Health, The University of Sydney, PoCoG, School of Psychology, The University of Sydney, \\ Australia \\ ${ }^{\mathrm{c}}$ Wiser Healthcare, ASK-GP Centre of Research Excellence, Sydney School of Public Health, The University of Sydney, NSW, Australia \\ ${ }^{\mathrm{d}}$ ASK-GP Centre of Research Excellence, Sydney School of Public Health, The University of Sydney, NSW, Australia \\ e ASK-GP Centre of Research Excellence, Sydney School of Public Health, the University of Sydney, NSW, 2006, Australia, Sydney School of Nursing, the \\ University of Sydney, NSW, Australia \\ ${ }^{\mathrm{f}}$ ASK-GP Centre of Research Excellence, Sydney Medical School, University of Sydney, NSW, Australia \\ ${ }^{g}$ ASK-GP Centre for Research Excellence, Centre for Research in Evidence-Based Practice, Bond University, Gold Coast, QLD, Australia \\ ${ }^{\text {h }}$ CEMPED, Wiser Healthcare, ASK-GP Centre of Research Excellence, Sydney School of Public Health, The University of Sydney, NSW, Australia
}

\section{A R T I C L E I N F O}

Article History:

Available online: 18 May 2017

Keywords:

shared decision making

Australia

policy

consumers

\begin{abstract}
A B S T R A C T
Shared decision making (SDM) is now firmly established within national clinical standards for accrediting hospitals, day procedure services, public dental services and medical education in Australia, with plans to align general practice, aged care and disability service. Implementation of these standards and training of health professionals is a key challenge for the Australian health sector at this time. Consumer involvement in health research, policy and clinical service governance has also increased, with a major focus on encouraging patients to ask questions during their clinical care. Tools to support shared decision making are increasingly used but there is a need for more systemic approaches to their development, cultural adaptation and implementation. Sustainable solutions to ensure tools are kept up-to-date with the best available evidence will be important for the future.
\end{abstract}

\section{A R T I K E L I N F O}

\section{Artikel-Historie:}

Online gestellt: 18. Mai 2017

\section{Schlüsselwörter:}

partizipative Entscheidungsfindung

Australien

Politik

Konsumenten

\section{Z U S A M M E N F A S S U N G}

Partizipative Entscheidungsfindung (PEF) ist in Australien mittlerweile fest in den nationalen klinischen Standards für die Akkreditierung von Krankenhäusern, Tageskliniken und öffentlichen Zahnarztpraxen sowie in der medizinischen Ausbildung verankert; und es bestehen Pläne, diese auf allgemeinmedizinische Praxen, Alten- und Behinderteneinrichtungen auszuweiten. Die Implementierung dieser Standards und die entsprechende Ausbildung von Gesundheitsfachkräften stellen für den australischen Gesundheitssektor derzeit eine der wichtigsten Herausforderungen dar. Die Einbindung der Konsumenten in Gesundheitsforschung, Gesundheitspolitik und Steuerung der klinischen Leistungserbringung hat ebenfalls zugenommen, wobei der Schwerpunkt darauf liegt, Patienten zu ermutigen, im Rahmen ihrer medizinischen Versorgung Fragen zu stellen. Immer häufiger werden Instrumente zur Unterstützung partizipativer Entscheidungsfindung genutzt, ihre Entwicklung, ihre kulturelle Adaptation und Implementierung erfordern jedoch stärker systemisch ausgerichtete Ansätze. Für die Zukunft wird es nötig sein, nachhaltige Lösungen zu entwickeln, um zu gewährleisten, dass diese Entscheidungshilfen auf der Grundlage der besten verfügbaren Evidenz ständig aktualisiert werden.

\footnotetext{
* Corresponding Author: Professor Lyndal Trevena, Room 321b, Edward Ford Building (A27), University of Sydney, NSW 2006 Australia.

E-mail: lyndal.trevena@sydney.edu.au (L. Trevena).
}

Introduction to Australia, its health system and a health snapshot

Australia currently has a population of approximately 24.2 million people [1]. Australians enjoy one of the highest life 
expectancies in the world with males born between 2012 and 2014 expecting to live until 80.3 years and for females, until 84.4 years [2]. Coronary heart disease remains the leading cause of death, accounting for 13\% all deaths in 2013. Cancer is the leading cause of disease-burden followed by cardiovascular disease, mental and substance abuse disorders, musculoskeletal disease and injury. However, $63 \%$ of Australian adults (11.2 million people) were overweight or obese in 2014-15 with 5 million of these being obese. Aboriginal and Torres Strait Islander peoples in Australia continue to have lower life expectancy and much higher rates of diabetes, kidney disease, heart disease and injury. Over half of Australians have very poor or marginal health literacy, meaning they have inadequate skills to meaningfully engage in health care and shared decision making (SDM), and this has been linked to worse chronic disease outcomes [3]. Australia spends about $9.4 \%$ of Gross Domestic Product (GDP) on health, in line with the average health expenditure of $9.3 \%$ for OECD countries [2].

Healthcare costs in Australia are funded by a mix of government, private health insurance and consumer out-of pocket expenses. The Australian Government's Medicare system provides a safety net to ensure access to essential healthcare. General Practitioners (GPs) and other members of the primary health care team (community nurses, pharmacists, allied health, dentists etc.) are usually the first point of contact with over $80 \%$ of all Australians seeing a GP at least once per year. Most medical and some allied health services are funded by a fee-for-service system called the Medicare Benefits Schedule (MBS). Most essential medication is subsidised by the Pharmaceutical Benefits Scheme (PBS). These systems are administered by the national Australian Government, whilst hospital care is administered by the seven State and Territory governments. These different jurisdictions have relevance to the complexity of SDM implementation in policy and practice.

\section{Australian policy developments in shared decision making}

Since our 2011 manuscript, the interest in SDM in Australia has increased and this is evident from the incorporation into policy, or discussion about, SDM by a number of national and state organisations. For example, the Australian Commission on Safety and Quality in Health Care (ACSQHC), who lead and coordinate national improvements in safety and quality in health care, hosted national symposiums about SDM in 2013 and 2014 to which representatives from stakeholder health organisations were invited. In conjunction with the ACSQHC and the National Health and Medical Research Council (NHMRC), SDM researchers also hosted Australia's inaugural symposium on SDM Research, with a view to encouraging collaboration and raising awareness of SDM among Australian clinicians and health organisations. An 'awareness-raising' article resulting from this was published in the centenary issue of the Medical Journal of Australia [4].

The ACSQHC have also extended their earlier work [5] by developing several programs in SDM, Health Literacy and Partnering with Consumers. In 2017 they plan to release the second version of the Australian 'National Safety and Quality Health Services Standards' and by 2019 , all health services will be assessed against these standards for accreditation [6]. The evolution of "Standard Two: Partnering with Consumers" in the 2012 version to the new version in 2017 is shown in Table 1 and demonstrates a clear shift towards patients being more actively involved in their own care if that is their preference.

The draft version of the new standards go further to explicitly mandate that "health services have processes for clinicians to partner with patients and/or their substitute decision maker to plan, communicate, set goals and make decisions about the current and future care". These standards apply for accreditation of all public and private hospitals, day procedure services and public dental

\section{Box 1: Key components of the Australian Charter of} Healthcare Rights

Access: I have the right to health care

Safety:I have a right to receive safe and high quality care

Respect: I have a right to be shown respect, dignity and consideration

Communication: I have a right to be informed about services, treatment,

options and costs in a clear and open way

Participation: I have a right to be included in decisions and choices about my care

Privacy: I have a right to privacy and confidentiality of my personal information Comment: I have a right to comment on my care and to have my concerns addressed

services in Australia. There has also been a change to begin aligning general practice, aged care and disability service accreditation with this same framework and process. The Royal Australian College of General Practitioners (RACGP) states that patients have the right to make informed decisions about their health and that "the clinical team must demonstrate how they provide information to their patients about the purpose, importance, benefits and possible costs of proposed investigations, referrals or treatments." ACSQHC has also established an Expert Advisory Committee to provide oversight and advice on the development of safety and quality strategies, tools and resources for primary care. The committee includes representation from audiology, podiatry, nursing, dentistry, psychology, consumers, pharmacy, optometry and general practice. This process of wider consultation will occur from mid-2017.

Further documentation of the right of patients to be informed and involved in their healthcare is supported by the requirement for all health organisations in Australia to have an easily accessible version of the "Australian Charter of Healthcare Rights". This Charter comprises seven core components (See Box 1).

The ACSQHC has also commissioned the Australian Atlas of Healthcare Variation [7] which has highlighted variation in antimicrobial prescribing, diagnostic and surgical interventions, psychotropic and mental health treatment, opioid prescription and interventions for chronic disease. The ACSQHC has explicitly identified SDM as a strategy to address unwarranted clinical variation. The Australian specialist colleges have also participated in the Choosing Wisely international movement but as yet there is no explicit inclusion of SDM as a strategy for reducing over-diagnosis and over-treatment.

\section{Patient and public involvement in SDM policy and research}

\section{Consumer involvement in policy}

The peak body for consumer representation in Australia remains the Consumers Health Forum, which has national and state branches. Members of these not-for-profit organisations are actively engaged in policy, advocacy, health service planning and research where possible and these organisations run a range of training programs for their members.

There has been growing interest in citizen's juries as another mechanism for engaging consumers in health decision-making and policy [8]. For example, in the state of Victoria, a jury of 78 Australians met daily for six-weeks to explore evidence and question experts to come up with 20 action points to address the growing problem of obesity in our community. ${ }^{1}$ Some of the requests they put forward were for better health ratings on food labels,

\footnotetext{
1 https://www.vichealth.vic.gov.au/programs-and-projects/victorias-citizensjury-on-obesity.
} 
Table 1

Evolution of Partnering with Consumers (Standard Two).

\begin{tabular}{|c|c|c|}
\hline 2012 Standard Two & 2017 Draft Standard Two & Change \\
\hline Health Service Level & Health Service Level & Health Service Level \\
\hline Consumer partnership in service planning & Clinical governance and quality Improvement & Continued emphasis on consumer engagement in \\
\hline Governance structures are in place to form & systems to support partnering with consumers & service governance and design but a distinct shift \\
\hline partnerships with consumers and/or carers & Systems are designed and used to support patients, & from consumers being informed about health \\
\hline Consumer partnership in designing care & carers, families and consumers to be partners in & service performance and design to being partners \\
\hline Consumers and/or carers are supported by the & healthcare planning, design, measurement and & and co-creators of service design, delivery and \\
\hline health service organisation to actively participate & evaluation & quality improvement. The new standards also \\
\hline $\begin{array}{l}\text { in the improvement of the patient experience and } \\
\text { patient health outcomes }\end{array}$ & $\begin{array}{l}\text { Partnering with consumers in organisational } \\
\text { design and governance }\end{array}$ & $\begin{array}{l}\text { require training for clinicians in partnering with } \\
\text { consumers and monitoring and reporting on the }\end{array}$ \\
\hline $\begin{array}{l}\text { Consumer partnership in service measurement } \\
\text { and evaluation }\end{array}$ & $\begin{array}{l}\text { Consumers are partners in the design and } \\
\text { governance of the organisation }\end{array}$ & consumer partnership processes. \\
\hline
\end{tabular}

Consumers and/or carers receive information on

the health service organisation's performance and contribute to the ongoing monitoring,

measurement and evaluation of performance for

continuous quality improvement. governance of the organisation

Individual patient level

Elements relevant to shared decision making were included in standards relating to governance, clinical handover, blood and blood products, prevention and management of pressure injuries and prevention and management of falls.

Individual patient level

Partnering with patients in their own care Systems that are based on partnering with patients in their own care are used to support the delivery of care. Patients are partners in their own care to the extent that they choose.

Health Literacy

Health service organisations communicate with

Consumers to provide feedback on patient information publications and this to be incorporated. Consideration of patients' capacity to understand health information. Patient

information to be provided about infection control, medicines information, blood and blood products, management of pressure sores, and rapid

deterioration and escalation of care. banning junk food and beverage marketing to children, imposing a $20 \%$ sugar tax and to establish fast-food exclusions zones around schools, sporting clubs, youth and community centres.

\section{Consumer involvement in research}

There has also been a shift towards greater involvement with consumers in designing and reviewing research proposals for grant applications. Furthermore, in 2013 Australia's National Health and Medical Research Council (NHMRC) established a Community and Consumer Advisory Group (CCAG) to provide high-level strategic advice on health and medical research matters from the consumer and community perspective ${ }^{2}$. In 2016, the Consumers Health Forum and the NHMRC released an update on their 'Statement on Consumer and Community Involvement in Health and Medical Research'. ${ }^{3}$ This document provides researchers with a roadmap for the many ways that consumers can be involved in research.

\section{Training for health professionals}

There has been increasing interest in SDM training and skills development mainly from health organisations charged with implementing the new standards. Some of the medical specialty colleges have also started to recommend and include training in health communication and SDM but this has not been standardised nor systematised [9]. The Royal Australian College of General Practitioners (RACGP), in conjunction with ACSQHC, has developed an online 'risk communication' module which is available to College members as part of its suite of continuing professional development options but the impact of this has not been evaluated.

\footnotetext{
2 (https://www.nhmrc.gov.au/about/nhmrc-committees/previous-committeesand-advisory-groups/community-and-consumer-advisory-group).

3 (https://www.nhmrc.gov.au/guidelines-publications/s01).
}

Undergraduate health students' exposure to SDM teaching and learning is patchy and largely reliant on local champions with expertise to drive this into local curricula. However, the Australian Medical Council (AMC) standards for accrediting medical schools now includes the requirement that medical graduates can "Elicit patients' questions and their views, concerns and preferences, promote rapport, and ensure patients' full understanding of their problem(s); Involve patients in decision- making and planning their treatment, including communicating risk and benefits of management options." [10]

\section{Current data on the experience of patients in Australia}

State based initiatives have also been introduced to capture the experience of patients who have been hospitalised. The Bureau of Health Information in New South Wales (NSW) is a board-governed organisation that publishes independent reports about the performance of the NSW public healthcare system. The NSW Patient Survey Program asks patients each month about their recent experience with the public healthcare system, which includes questions as part of the NSW Patient Survey Program. Latest available data from the 2014 survey reported that $60 \%$ of patients said they were 'definitely' involved in decisions about their care [11].

\section{Tools and resources to support shared decision making}

Interest in enhancing the implementation and availability of tools to support SDM in Australia has also gathered momentum over the past six years, although, like many other countries, the development and updating of tools is ad hoc and reactive. One notable example of SDM facilitation has been with PSA screening for prostate cancer and the Royal Australian College of General Practitioners (RACGP). The RACGP guidelines are aligned to an NHMRC-commissioned evidence summary, both of which recommend SDM for asymptomatic men who request a PSA test. As part of this evidence-summary/guideline package, the RACGP also 
developed a short-form patient decision aid which is one of the most frequently downloaded resources from their website (personal communication). Similarly, the ACSQHC commissioned the development of brief patient decision aids to facilitate SDM about antibiotic prescribing for acute respiratory infections [12]. The latter are currently being evaluated in an NHMRC-funded randomised controlled trial.

Australian researchers have been pioneers in the development and use of generic questions and question prompt lists with this work continuing to evolve over the past six years. The early work in oncology Question Prompt Lists [9] has seen a series of these resources published on the NSW Cancer Institute portal. The work on training consumers to ask three questions $[13,14]$ has been extended from the original proof-of-concept trial to a feasibility study that trained patients via a waiting room video and more recently this has been adapted for adults with lower literacy and languages other than English. This latter work has included work with the adult education sector to improve health literacy and has for the first time shown that SDM training increases functional and critical health literacy [15]. The Australian Government's HealthDirect consumer portal is currently developing a question builder adapted from the US Agency for Research and Quality in Health Care.

A number of other prominent health organisations direct patients to 'question lists' to guide patients and their families through the types of things it is important to ask when making decisions about their health. Examples of this include the Cancer Council Australia Questions-to-ask-your-doctor information $[16]^{4}$ and the National Prescribing Service, who point consumers to 5-questionsto-ask-your-doctor within their Choosing Wisely Australia initiative. ${ }^{5}$ [17] The first national meeting of Choosing Wisely Australia was held in May 2017. Whilst direction towards question asking tools is growing, there is often little information explaining the value of shared decision making and the role question asking has in increasing the opportunity for patients to be involved in decisions about their health.

\section{Future challenges for SDM in Australia}

Whilst there has been an exciting shift towards greater patient involvement in healthcare decisions, scaling this up is not an easy task. The implementation of the new National Standards presents both opportunities and challenges. There will be a need for clarification of core competencies in SDM for patients and health professionals as well as meaningful measures of SDM implementation at the service level. There has not been any substantial discussion about certification of patient decision aids or other tools as this stage and there needs to be better familiarity with the International Patient Decision Aid Standards (IPDAS). These standards require that tools are regularly updated and use the best available evidence but mechanisms to ensure the sustainability of this have not yet been considered. Australia is a multi-cultural nation and there is a need to extend the SDM work with adaption of tools for vulnerable population groups. Early research has commenced on SDM with the elderly, lower literacy and patients from non-Western cultural backgrounds. Australia's multicultural population and geographical location within the Asia-Pacific region provides opportunities to extend this work on patient-centred care to lower resource countries. Questions remain about the extent to which SDM or its components and tools can be adopted in health care decisions where there is strong evidence for one option, such as with vaccination [18], and if so, in which contexts. Further exploration and specificity is required here.

We need to continue to work with our international partners to share resources and ideas to facilitate patient rights and empowerment, and SDM. We look forward to updating this field in the next edition.

\section{Conflict of Interest}

None declared.

\section{References}

[1] Australian Bureau of Statistics, Australian Demographic Statistics, Sep 2016. http://www.abs.gov.au/ausstats/abs@.nsf/mf/3101.0, 2016.(accessed 24.04.17).

[2] Australian Institute of Health and Welfare, Australia's health 2016. http://www.aihw.gov.au/australias-health/2016/, 2016.(accessed 24.04.17).

[3] Adams RJ, Appleton SL, Hill CL, Dodd M, Findlay C, Wilson DH. Risks associated with low functional health literacy in an Australian population. Med J Aust 2009;191(10):530-4.

[4] Hoffmann TC, Légaré F, Simmons MB, McNamara K, McCaffery K, et al. Shared decision making: what do clinicians need to know and why should they bother? Med J Aust 2014;201(1):35-9.

[5] McCaffery KJ, Smith S, Shepherd HL, Sze M, Dhillon H, et al. Shared decision making in Australia in 2011. Z Evid Fortbild Qual Gesundhwes 2011;105(4):234-9.

[6] Australian Commission on Saftey and Quality in Health Care National Standards program updates and consultations. https://www.safetyandquality. gov.au/our-work/assessment-to-the-nsqhs-standards/ national-standards-program-updates-and-consultations/, 2017.(accessed 03.04.2017).

[7] Australian Commission on Saftey and Quality in Health Care, Australian Atlas of Healthcare Variation. https://www.safetyandquality.gov.au/atlas/, 2015.(accessed 24.04.2017).

[8] Degeling C, Carter SM, Rychetnik L. Which public and why deliberate?-A scoping review of public deliberation in public health and health policy research. Soc Sci Med 2015;131:114-21.

[9] Clayton JM, Butow PN, Tattersall MH, Devine RJ, Simpson JM, et al. Randomized controlled trial of a prompt list to help advanced cancer patients and their caregivers to ask questions about prognosis and end-of-life care. J Clin Oncol 2007;25(6):715-23.

[10] Australian Medical Council, Standards for Assessment and Accreditation of Primary Medical Programs by the Australian Medical Council 2012. http://www.amc.org.au/files/d0ffcecda9608cf49c66c93a79a4ad549638bea0_ original.pdf, 2012.(accessed 24.04.2017).

[11] Bureau of Health Information, Patient Exprience Survey. http://www.bhi.nsw. gov.au/nsw_patient_survey_program, 2014.(accessed 24.04.2017).

[12] Coxeter PD, Del Mar CB, Hoffmann TC. Preparing Parents to Make An Informed Choice About Antibiotic Use for Common Acute Respiratory Infections in Children: A Randomised Trial of Brief Decision Aids in a Hypothetical Scenario. The Patient-Patient-Centred Outcomes 2017:1-12.

[13] Shepherd HL, Barratt A, Trevena LJ, McGeechan K, Carey K, et al. Three questions that patients can ask to improve the quality of information physicians give about treatment options: a cross-over trial. Patient Educ Couns 2011;84(3):379-85.

[14] Shepherd HL, Barratt A, Trevena LJ, McGeechan K, Carey K, et al. Can consumers learn to ask three questions to improve shared decision making? A feasibility study of the ASK (AskShareKnow) Patient-Clinician Communication $\operatorname{Model}((\mathrm{R}))$ intervention in a primary health-care setting. Health Expect 2016;19(5):1160-8.

[15] Muscat DM, Shepherd HL, Morony S, Smith SK, Dhillon HM, et al. Can adults with low literacy understand shared decision making questions? A qualitative investigation. Patient Educ Couns 2016;99(11):1796-802.

[16] Cancer Council Australia. Questions to Ask Your Doctor. http://www. cancer.org.au/about-cancer/after-a-diagnosis/questions-to-ask-yourdoctor.html. 2017.(Accessed 10.04.17).

[17] National Prescribing Service. 5 Questions to Ask your dctor or other healthcare provider. http://www.choosingwisely.org.au/resources/consumers/5questions-to-ask-your-doctor. 2017.(Accessed 10.04.17).

[18] Opel DJ. A Push for Progress With Shared Decision-making in Pediatrics. Pediatrics 2017;139(2):e20162526.

\footnotetext{
4 http://www.cancer.org.au/about-cancer/after-a-diagnosis/questions-to-askyour-doctor.html.

5 http://www.choosingwisely.org.au/resources/consumers/5-questions-to-askyour-doct.
} 